\title{
Correction to: Evaluating a screener to quantify PTSD risk using emergency care information: a proof of concept study
}

Willem F. van der Mei ${ }^{1 *}$, Anna C. Barbano ${ }^{2}$, Andrew Ratanatharathorn ${ }^{3}$, Richard A. Bryant ${ }^{4}$, Douglas L. Delahanty ${ }^{5}$, Terri A. deRoon-Cassini ${ }^{6}$, Betty S. Lai ${ }^{7}$, Sarah R. Lowe ${ }^{8}$, Yutaka J. Matsuoka ${ }^{9}$, Miranda Olff ${ }^{10,11}$, Wei Qi ${ }^{2}$, Ulrich Schnyder ${ }^{12}$, Soraya Seedat ${ }^{13}$, Ronald C. Kessler ${ }^{14}$, Karestan C. Koenen ${ }^{15}$, Arieh Y. Shalev ${ }^{2}$ and International Consortium to Predict PTSD

\section{Correction to: BMC Emerg Med 20, 16 (2020) https://doi.org/10.1186/s12873-020-00308-z}

The original article [1] contains an error in the presentation of institutional author, J Carel Goslings's name in the Acknowledgements sub-section which is presented correctly in this Correction article.

\section{Acknowledgements}

Members of the ICPP also include Yael Errera-Ankri, Sarah Freedman, Jessie Frijling, J Carel Goslings, Jan Luitse, Alexander McFarlane, Derrick Silove, Hanspeter Moergeli, Joanne Mouthaan, Daisuke Nishi, Meaghan O'Donnell, Mark Rusch, Marit Sijbrandij, Sharain Suliman, and Mirjam van Zuiden. We are grateful for the contributions of Paul O'Connor at the Nathan Kline Institute for his invaluable assistance in data management and quality assurance.

\footnotetext{
Author details

'Department of Population Health, New York University Langone Health, 227 E 30th St, New York, NY, USA. ${ }^{2}$ Department of Psychiatry, New York University School of Medicine, 1 Park Avenue, New York, NY 10016, USA. ${ }^{3}$ Department of Epidemiology, Columbia University Mailman School of Public Health, 722 W. 168th St, New York, NY 10032, USA. " School of Psychology, University of New South Wales, Sydney, NSW 2052, Australia. ${ }^{5}$ Department of Psychological Sciences, Kent State University, 144 Kent Hall, Kent, OH 44242, USA. ${ }^{6}$ Department of Surgery, Medical College of Wisconsin, 9200 W. Wisconsin Avenue, Milwaukee, WI 53226, USA. ${ }^{7}$ Department of Counselling,
}

Developmental, and Educational Psychology, Lynch School of Education and Human Development, Boston College, Campion Hall Room 313, 140 Commonwealth Avenue, Chestnut Hill, MA 02467, USA. ${ }^{8}$ Department of Psychology, Montclair State University, 1 Normal Avenue, Montclair, NJ 07043, USA. 'Division of Health Care Research, Center for Public Health Sciences, National Cancer Center Japan, 5-1-1 Tsukiji, Chou-ku, Tokyo 104-0045, Japan. ${ }^{10}$ Department of Psychiatry, Academic Medical Center, University of Amsterdam, Meibergdreef 9, 1105, AZ, Amsterdam, The Netherlands. ${ }^{11}$ Arq Psychotrauma Expert Group, Postbus 240, 1110 AE Diemen, The Netherlands. ${ }^{12}$ Department of Psychiatry and Psychotherapy, University Hospital Zurich, Box 1931, Lenggstrasse 31, 8032 Zürich, PO, Switzerland. ${ }^{13}$ Department of Psychiatry, Stellenbosch University, Private Bag X1, Matieland, Stellenbosch 7602, South Africa. ${ }^{14}$ Department of Health Care Policy, Harvard Medical School, 180 Longwood Avenue, Boston, MA 02115, USA. ${ }^{15}$ Department of Epidemiology, Harvard T.H. Chan School of Public Health, Kresge 505, 677 Huntington Avenue, Kresge Building, Boston, MA 02115, USA.

Published online: 29 June 2020

\section{Reference}

1. van der Mei WF, et al. Evaluating a screener to quantify PTSD risk using emergency care information: a proof of concept study. BMC Emerg Med. 2020;20:16 https://doi.org/10.1186/s12873-020-00308-z.

The original article can be found online at https://doi.org/10.1186/s12873020-00308-z.

*Correspondence: willem.vandermei91@gmail.com

'Department of Population Health, New York University Langone Health, 227 E 30th St, New York, NY, USA

Full list of author information is available at the end of the article

(C) The Author(s). 2020 Open Access This article is licensed under a Creative Commons Attribution 4.0 International License, which permits use, sharing, adaptation, distribution and reproduction in any medium or format, as long as you give appropriate credit to the original author(s) and the source, provide a link to the Creative Commons licence, and indicate if changes were made. The images or other third party material in this article are included in the article's Creative Commons licence, unless indicated otherwise in a credit line to the material. If material is not included in the article's Creative Commons licence and your intended use is not permitted by statutory regulation or exceeds the permitted use, you will need to obtain permission directly from the copyright holder. To view a copy of this licence, visit http://creativecommons.org/licenses/by/4.0/ The Creative Commons Public Domain Dedication waiver (http://creativecommons.org/publicdomain/zero/1.0/) applies to the data made available in this article, unless otherwise stated in a credit line to the data. 